\title{
LOS MAYORES PRODUCTORES AGRARIOS DE GALICIA EN LA SEGUNDA MITAD DEL SIGLO XVIII
}

\author{
ANGEL I. FERNANDEZ GONZALEZ 1 \\ Universidad de Santiago
}

\section{RESUMEN}

A través de una fuente poco conocida pero de gran utilidad y disponible para toda España, el «excusadom, hemos determinado el volumen de producción y el excedente obtenido por un amplio conjunto de las mayores explotaciones agrarias de Galicia en el siglo xviI. Nuestra principal conclusión ha sido que en Galicia, a diferencia de lo que parece haber sucedido en otras regiones de la España septentrional, no llegó a consolidarse una elite de explotaciones con capacidad para obtener un excedente apreciable, y que predominaban los campesinos que se hallaban por debajo del nivel de subsistencia. Insistimos en que este hecho debe ser considerado uno de los factores que dificultó la modernización del sector agrario gallego en el siglo XIX.

\section{ABSTRACT}

From a little known but very useful source, the «excusado», I have determined the production volume and the surplus obtained from a wide sample of large farms in the Spanish region of Galicia during xvilth century. The main conclusion is that, in contrast to other regions in northern Spain, no group of large farmers with a marketable surplus was formed, and most peasant farmers lived below subsistance levels. I argue that this was a major factor in hindering the modernization of Galician agriculture during the xIxth century.

\section{INTRODUCCION}

Uno de los temas de la historia agraria de España insuficientemente tratados por la investigación, y cuyo estudio se hace cada vez más necesario, es el del nivel de diferenciación interna del campesinado. La principal dificultad para abordarlo se deriva de la falta de fuentes y metodologia adecuadas para

${ }^{1} \mathrm{Mi}$ agradecimiento por sus observaciones y sugerencias a los profesores Fausto Dopico y Joám Carmona. 
realizar un análisis lo suficientemente exhaustivo, que vaya más allá del marco local o comarcal y permita establecer comparaciones minimamente coherentes. Con este trabajo pretendemos precisamente contribuir a un mejor conocimiento del estrato más alto de los productores agrarios de Galicia, de los que hemos denominado «mayores productores». Para ello recurriremos a una fuente poco utilizada hasta el momento, las contabilidades del «excusado», que nos permitirán estimar el producto bruto obtenido en las mayores explotaciones de un amplio territorio en diversos momentos de la segunda mitad del siglo XVIII.

Las cuentas presentadas a la Hacienda real por los administradores del «excusado» recogen lo que pagaba en concepto de diezmo la explotación agraria más importante de cada feligresia, habitualmente denominada «casa mayor diezmera» o «casa excusada». La Corona española había conseguido del Papado en el siglo XVI el derecho a percibir esta porción de los diezmos de cada parroquia, pero siempre se había limitado a recaudar de cada diócesis una cantidad fija anual en dinero. A principios de la década de 1760 la Hacienda optó, sin embargo, por abandonar este sistema y pasó a administrar y percibir directamente los diezmos de las casas excusadas. Esta es la razón de que desde 1763 hasta principios del siglo XIX, aunque de forma intermitente, dispongamos de relaciones casi siempre muy exhaustivas de lo percibido por este concepto.

No se trata de dar respuesta a todas las preguntas que podrian hacerse en torno a las caracteristicas del tipo de explotaciones que vamos a analizar y su papel dentro del sector agrario. Nuestro propósito es complementar los análisis tradicionales de los procesos de diferenciación, basados en la cuantificación del patrimonio territorial y ganadero de los productores agrarios, a partir del anälisis de las cifras del producto bruto efectivamente obtenido por los mismos. Aunque es evidente que no está exento de un cierto margen de error, el método que proponemos presenta indudables ventajas ${ }^{2}$. La estimación del producto neto y el excedente comercializable de cada explotación es un punto de partida relativamente objetivo para apreciar regularidades y diferencias regionales o comarcales y para, por ejemplo, precisar si los mayores productores

2 Hace tiempo que los investigadores manifiestan su descontento con los métodos que clasifican las explotaciones agrarias de acuerdo con la cantidad de tierra disponible. Ya Clapham, (1951, p. 165) insistia en que la cantidad de tierra necesaria para que una familia campesina pudiese vivir «en un bienestar razonable» variaba mucho de unas regiones a otras, y argumentaba que para distinguir entre explotaciones pequeñas, medianas y grandes debería tenerse en cuenta no la superficie cultivada, sino el producto neto obtenido. Citado por Blum (1978, p. 104). 
estaban libres de los peligros de las crisis de subsistencias, o gozaban de una cierta capacidad de acumulación. Se trata, en suma, de desarrollar la metodología adecuada para la utilización de esta fuente y de contribuir a aclarar en qué medida las comunidades rurales estaban polarizadas social y económicamente.

Es bien conocido que la evolución de la agricultura gallega a lo largo de la Edad Moderna tuvo caracteristicas semejantes a la de otras agriculturas del norte de España. La organización del proceso productivo quedó en manos de pequeñas explotaciones dirigidas y cultivadas por familias campesinas que disponían de buena parte de sus tierras a través de foros y arriendos. Los sistemas de cultivo se orientaron hacia una progresiva intensificación del uso de la tierra y se basaron en una amplia utilización del espacio inculto ${ }^{3}$. A nivel comarcal existían, por supuesto, diferencias que se manifestaban en aspectos tales como la mayor o menor importancia de los contratos enfitéuticos, el mayor o menor peso de la ganadería o del vino respecto a la producción de cereales, las formas de aprovechamiento del espacio inculto disponible o la extensión de actividades complementarias de la agricultura como la manufactura textil o la arriería. Pero no cabe duda de que la explotación «campesina» era la protagonista de los procesos productivos.

También está comprobado que a nivel local los perceptores de rentas y diezmos (nobles, hidalgos, curas, priores...) ocupaban casi siempre un lugar preeminente, claramente distanciado de los demás vecinos, pero es más dificil precisar si aquellos cuyas fuentes de ingresos eran la labranza, la manufactura o el comercio, alcanzaban posiciones semejantes. No sabemos lo suficiente acerca del grado de diferenciación interna de un campesinado al que contemplamos con demasiada frecuencia como un grupo relativamente homogéneo de pequeños y medianos cultivadores. Que había pequeños cultivadores y familias «sin tierra» es algo fácil de detectar, y también lo es que para obtener los ingresos necesarios para subsistir tenian que trabajar a jornal para los que disponian de más tierras, o emigrar a Castilla, o recurrir a la tejeduria y a otras actividades secundarias o terciarias. Lo que no resulta tan fácil es conocer la proporción de la población rural que representaba este estrato inferior. Y, si exceptuamos la información proporcionada por algunas investigaciones ${ }^{4}$, tam-

Sobre estas cuestiones, véase Dopico y Rodríguez (1981) y Saavedra y Villares (1985).

${ }^{4}$ En su estudio sobre una comarca de las Rias Bajas, Pérez Garcia (1979) se ha esforzado en pre. cisar este grado de diferenciación, y, de acuerdo con lo observado por estudios similares en varias re giones de Francia, ha detectado un grupo minoritario de explotaciones excedentarias, otro de explotaciones que producen lo suficiente para cubrir sus necesidades $y$ un numeroso grupo de campesinos dependientes, incapaces de producir los alimentos que precisan. Estratificaciones semejantes son también constatadas por Villares (1982) en las comarcas del sur de Lugo. 
poco podemos determinar qué proporción de campesinos estaban en mejor situación y cuál era su capacidad para asegurar la reproducción de sus explotaciones.

Los datos del excusado pueden arrojar más luz sobre este tipo de cuestiones porque, como deciamos, permiten precisar el volumen del producto bruto y la estructura de cultivos de un número muy amplio de explotaciones; y porque, acudiendo a otras fuentes, como el Catastro de Ensenada, es posible realizar una estimación de su producto neto y de su capacidad excedentaria. El hecho de que las contabilidades del excusado se conserven para todo el territorio español hace que este tipo de análisis tenga aún mayor interés por las grandes posibilidades comparativas que ofreces.

\section{LAS FUENTES. PROBLEMAS E INTERPRETACION}

En nuestro estudio utilizaremos los datos relativos a las mayores casas diezmeras de las siguientes diócesis: Lugo, con 1.100 parroquias en los años 1763-1766; Orense, con 524 en los años 1763, 1765 y 1766, y Santiago, con 1.024 parroquias en el año $1804^{6}$. Se trata de cuentas que recogen con sumo detalle las cantidades pagadas de cereales, vino, castañas, habas, lino, nabos, hierba, productos ganaderos y otras producciones menudas. Especifican asimismo el nombre del titular de la explotación. Es posible, por tanto, abarcar un amplio conjunto territorial utilizando datos homogéneos que se refieren a explotaciones individuales perfectamente identificables, que comparten la característica de ser las más importantes (en cuanto a volumen de producción, pero no necesariamente a la dimensión de su patrimonio) de sus respectivas parroquias.

La correcta interpretación de este tipo de datos plantea, sin embargo, ciertos problemas. En primer lugar, el excusado presenta los problemas típicos que afectan a toda contabilidad decimal. Hay que tener en cuenta que algunos productos agrarios no diezmaban, o lo hacian en una proporción inferior a la décima parte. Las castañas, las habas o los nabos, por ejemplo, están exentos en algunas áreas, aunque casi siempre por ser de escasa producción. De la hierba, la madera, o de los distintos tipos de plantas cultivadas para ser utiliza das como abono, no solia pagarse diezmo, por cuanto constituian casi siempre

5 En el Archivo General de Simancas (AGS) se conservan 39 legajos con documentación sobre diezmos entre los que se encuentran estas contabilidades que, con diversas lagunas, se refieren a todas las diócesis de España. Dirección General de Rentas, 2." Remesa, legs. 614-651.

6 AGS, DGR, 2. ${ }^{\text {a }}$., legs. 640, 647, 648. 
inputs intermedios necesarios para obtener otros productos que sí estaban sujetos. Lo mismo puede decirse de la paja de los cereales, que tampoco es contabilizada. El subregistro de la producción de patatas no reviste especial importancia a mediados del xviII, cuando la extensión de este cultivo era muy limitada, pero si la tiene a principios del XIX, al menos en el caso gallego, ya que en algunas áreas la patata no quedó sujeta al pago del diezmo.

Las diversas producciones ganaderas, por su parte, estaban gravadas por el diezmo, aunque no siempre se pagaba el $10 \%$ exacto. Sucedía así con las crias, pues si su número era inferior a diez se pagaba una cantidad fija en dinero por cabeza que no solía equivaler al valor de mercado de lo que hubiera debido pagarse en especie. Algo parecido acontecía con el diezmo de la leche, por el que se pagaba una cantidad fija en manteca o dinero que tampoco era proporcional a la leche obtenida o al número de vacas que la producían.

Un segundo tipo de problemas tiene que ver con el propio concepto de excusado. Es importante verificar si las cifras que utilizamos reflejan realmente el diezmo de la producción total de la explotación seleccionada, y sabemos que esto no siempre era asi. La costumbre general en las diócesis de Galicia, como en muchas otras, era que de la producción obtenida en tierras pertenecientes a parroquias limítrofes a aquella en la que residía el cultivador, éste pagase la mitad del diezmo de esa parte de su cosecha a los perceptores de las mismas. Es muy improbable, no obstante, que en nuestro caso este sesgo fuese apreciable porque, en primer lugar, no existia ganadería trashumante. En segundo lugar, porque una parte considerable de las feligresías eran lo suficientemente extensas como para hacer inviables los desplazamientos frecuentes a campos de cultivo alejados de la vivienda del campesino, tanto más necesarios cuanto más predomina el policultivo. $Y$ en tercer lugar, porque es habitual que los límites parroquiales sigan el curso de obstáculos orográficos naturales, como ríos o montes, lo que hacía difícil el desplazamiento para cultivar tierras ubicadas fuera de la parroquia de residencia ${ }^{7}$.

Un último problema a tener en cuenta es el hecho de que la explotación seleccionada como «casa mayor diezmera» podía no ser la de mayor producción de la parroquia. No podemos descartar que los administradores o arrendatarios escogiesen como «casa excusada» a aquella explotación que ofreciese una mejor relación entre el ingreso potencial de la venta de su diezmo y los costes de recaudación y comercialización del mismo, lo que no tenía por qué suceder con la explotación de mayor volumen de producción.

7 Las Respuestas Generales del Catastro muestran que el trasvase de diezmos entre parroquias, aunque implicase a cierto número de cultivadores, afectaba a un volumen de producción muy pequeño, y por ello las cifras declaradas en concepto de diezmo de «forasteros» suelen ser muy bajas. 
Pese a todo, y salvo excepciones, no cabe duda de que estamos ante una de las pocas fuentes que nos proporciona información válida sobre la capacidad productiva de los cultivadores más importantes de Galicia. Nuestro primer objetivo será identificarlos. Quiénes son, cuál es la dimensión y la composición de sus hogares, con qué cabaña ganadera cuentan, si pagan o no rentas, o si tienen fuentes de ingresos no procedentes de actividades agropecuarias, son cuestiones que puede ayudar a resolver el Catastro de Ensenada. A pesar de los diez años que median entre las primeras cuentas del excusado y los libros de Respuestas Generales del Catastro, éstos ofrecen datos muy valiosos sobre la composición del hogar y los oficios de los miembros de la familia, sobre los bienes de que disponen en la demarcación catastrada (casas, tierras, ganado, etc.), o sobre las pensiones que los gravan (renta de la tierra, primicia, voto, censos, misas, etc.).

Nuestro siguiente paso será presentar las cifras de la producción bruta obtenida en sus explotaciones, prestando especial atención a cereales, castañas, habas y vino. Finalmente evaluaremos el producto neto disponible una vez reservada la simiente para la próxima cosecha, y después de pagadas renta y diezmos, y satisfechas las necesidades alimenticias de los miembros del hogar. Las variables que consideramos son, pues, el producto bruto, el producto neto y el excedente, obtenido deduciendo del producto neto el consumo familiar.

Aunque seria deseable, no disponemos de la información necesaria para realizar un balance completo de todos los ingresos y gastos de las explotaciones analizadas, y por ello nos centraremos en lo que con toda probabilidad era el núcleo fundamental del haber (producción agrícola y ganadera) y del debe (consumo familiar, renta de la tierra y diezmo). Supondremos que otras producciones (lino, madera, pescado...) o ingresos (por actividades no agrarias) sirven para satisfacer necesidades de la familia que no hemos considerado (fabricación de vestimenta, adquisición de bienes y servicios no producidos por ella misma, etc.), para cubrir costes que no hemos incluido en los cálculos (las mermas por almacenamiento, por ejemplo), o para pagar los impuestos reales y otras exacciones señoriales o fiscales que tampoco consignamos ${ }^{8}$. La explicación detallada de los supuestos y la metodología utilizada en nuestros cálculos la exponemos en los apéndices.

${ }^{8}$ Hay que señalar que, al contrario de lo que sucedia en otras regiones, la carga que suponian los derechos de señorio no era aquí comparable a la de diezmos y rentas territoriales, tal como destaca Saavedra (1992b), pp. 52-67. Es también importante destacar que en el caso gallego no tiene sentido considerar que una parte del cereal producido se destine a la alimentación del ganado. Recordemos que, salvo el mijo menudo, todos los cereales producidos (trigo, centeno, maiz) eran aptos para el consumo humano, y que la cebada y la avena tienen una presencia 


\section{LOS MAYORES PRODUCTORES AGRARIOS: IDENTIFICACION}

De una primera observación del listado de titulares de las «casas excusadas» se deduce algo muy simple y que no es ninguna sorpresa: en contadas ocasiones figuran haciendas cuya explotación directa corresponda a personas o instituciones fácilmente reconocibles. Nobles, conventos, órdenes militares, jerarquías eclesiásticas, o los administradores de los mismos, brillan por su ausencia a pesar de que sabemos que tales instituciones y familias contaban con importantes patrimonios territoriales. Por el contrario, la lista se compone de gente con nombres y apellidos corrientes, de los que una parte reciben el tratamiento de «Don». Son los cultivadores directos, sean campesinos o hidalgos, que emplean fuerza de trabajo familiar o criados y jornaleros, los que pagan el diezmo de un conjunto de tierras por las que también suelen pagar rentas al dominio directo. $Y$ es precisamente para saber algo de ellos por lo que hay que acudir al Catastro de Ensenada.

El ingente trabajo que supondría la consulta de los libros correspondientes a las más de 1.600 parroquias que componian las diócesis de Lugo y Orense, nos ha obligado a seleccionar una muestra de 239 casas excusadas cuyo titular puede ser claramente identificado en el Catastro. Esta muestra comprende diversas comarcas de la Galicia central y centro-oriental, y en su selección hemos procurado incluir explotaciones con características diferentes, desde aquellas cuyas principales producciones eran los cereales, tanto el centeno como el maiz, y la cría de ganado, hasta aquellas otras en las que la vid era el cultivo fundamental y la ganadería tenía un papel secundario.

Entre los titulares de estas explotaciones es claro el predominio de los conceptuados por el Catastro como labradores (el $71 \%$ ), de los cuales un tercio tienen además otro tipo de oficios y actividades productivas, en especial la arriería, la manufactura y el comercio al por menor. Algunos de ellos perciben pequeñas rentas y otros ceden ganado a terceros en aparcería. El $21 \%$ son hidalgos o pequeños nobles, y el resto $(8 \%)$ son presbiteros, abogados y escribanos, o figuran como simples titulares de las explotaciones sin participación personal en las labores agrarias y sin otra actividad por la que obtengan ingresos.

muy escasa. Esto quiere decir que existian diversas formas de alimentarlo sin tener que despilfarrar cereales o castañas: el ganado consumía hierba y arbustos de prados, montes y barbechos; centeno, cebada o avena en verde, y nabos. De todo lo que acaba siendo diezmado sölo una mínima parte (mijo menudo para las aves y castañas para los cerdos) sería posteriormente destinado a animales. 
No resulta extraño, por tanto, ya que hablamos de labradores acomodados y de hidalgos rurales, que nos encontremos con hogares especialmente grandes, con una media de 8,7 individuos por hogar, incluso si los comparamos con la dimensión media de las familias de la Galicia interior, superior a la del resto del país. Esta característica es notoria en los hogares hidalgos, con mayor número de miembros (10 de media) que los campesinos $(7,2)$, así como una mayor proporción de criados. Un ejemplo extremo era el del hidalgo D. Lucas Somoza, de S. Martiño de Laiosa (Incio), soltero de 33 años que vivía con dos hermanos mayores de edad, siete criados y cuatro criadas. Hogares especialmente extensos eran también los del hidalgo D. Diego Rivadeneira, de Teilán (Bóveda), que tenía en casa a tres hijos mayores, uno de ellos casado, una hija, una sobrina, tres nietos, tres criados y cuatro criadas; o el de Francisco Carballo, labrador de Veiga (Pobra de Brollón), con el que convivían su esposa, su madre, tres hijos y dos hermanos.

La comparación de estas cifras con las obtenidas por P. Saavedra a partir del propio Catastro, con medias de 5,76 personas por hogar en Lugo y 4,33 en Orense, pone de manifiesto que las explotaciones con mayor volumen de producción estaban también entre las que contaban con hogares más extensos ${ }^{9}$. Y no sólo eso: también contaban con cabañas ganaderas superiores a la media gallega, en torno a las 15 cabezas por vecino ${ }^{10}$. La media de las 239 explotaciones estudiadas es de 51 cabezas ( 8,5 de vacuno, 32 de ovino-caprino y 9 de porcino, que son las especies más generalizadas). No cabe duda de que estos valores medios esconden diferencias entre unas y otras explotaciones, pues en las zonas de mayor producción vitícola, al sur de Lugo, las cifras de ganado por vecino son más bajas, 30 cabezas por explotación, y en comarcas como el Ribeiro son todavía menores, mientras que en otras áreas son claramente superiores. Estas diferencias, ya apreciadas por otros investigadores ${ }^{11}$, deben ser tenidas en cuenta a la hora de interpretar y comparar las cifras de producción agrícola en cada comarca, pues el hecho de que el diezmo no gravase el producto ganadero con la misma eficacia que la producción de cereal o de vino se traducirá en una aparente menor capacidad productiva de los diezmeros de Lugo o de la Galicia central que no se ajusta a la realidad.

Estamos, en definitiva, ante explotaciones gestionadas por campesinos e

9 Saavedra (1988).

10 De las cuales 3,66 eran de vacuno, 2,34 de porcino, 8,57 de ovino y caprino y 0,53 de caballar y mular. Cordero, Dopico y Rodriguez (1983), p. 76.

11 Ibidem, p. 77; Saavedra (1992a), pp. 117-119. 
hidalgos, con hogares extensos y cabañas ganaderas relativamente numerosas, y que casi siempre pagan rentas forales a instituciones eclesiásticas, a la nobleza y a diversas casas hidalgas ${ }^{12}$.

\section{PRODUCTO BRUTO, PRODUCTO NETO Y EXCEDENTE DE LAS MAYORES EXPLOTACIONES AGRARIAS. VOLUMEN Y COMPOSICION}

Para determinar el volumen y la composición del producto bruto contamos con fuentes que cubren la práctica totalidad de Galicia, aunque de forma desigual y en momentos diferentes. Para la Galicia interior utilizaremos datos referidos a tres cosechas (1763-64-65) y a 1.624 explotaciones de las diócesis de Lugo y Orense, datos que nos permitirán obtener valores representativos de una cosecha «media». Nos serviremos también de las cifras del diezmo pagado por 1.024 explotaciones de la diócesis de Santiago, representativas de la Galicia occidental, en 1804 , con un volumen de producción superior al de un año agrario «medio» 13 .

Los principales productos obtenidos en las explotaciones de la Galicia interior eran los cereales (trigo, centeno, maíz y mijo menudo) y el vino, a los que hay que sumar castañas, habas, lino, nabos y producciones ganaderas. El valor del diezmo de cereales, vino, castañas y habas rebasaba el $80 \%$ del total, tanto en Lugo, algo más del 80 , como en Orense, el $86 \%$. El valor conjunto del de lino, nabos y ganado oscilaba entre el $12 \%$ de Orense y el $15 \%$ de Lugo.

En el cuadro 1 hemos resumido los datos del total producido en cada diócesis, y ofrecemos también las medias de cada grupo de productos por explo-

12 No debemos olvidar tampoco que estas características corresponden a las comarcas centrales y orientales de Galicia, y que al extrapolarlas a las demás introducimos un cierto margen de error. Hay indicios de que en la Galicia occidental el tamaño de los hogares y su patrimonio territorial y ganadero eran inferiores, y de que la presencia de la hidalguía también era menor. Las propias contabilidades del excusado ponen de manifiesto la menor presencia de la hidalguia. El tratamiento de Don, aplicado casi exclusivamente a hidalgos, eclesiásticos, jueces, abogados o escribanos, figura en el $27 \%$ de las parroquias de la diócesis de Lugo y en algo más del $30 \%$ de la de Orense, mientras que en la de Santiago (año 1804) y en la de Mondoñedo (años 1797-98.99) supera escasamente el $11 \%$.

13 Las pruebas de que las cifras del trienio considerado son representativas de un nivel de producción «medio» y de que 1804 fue un buen año agrario en la Galicia occidental las aportamos en el apéndice 2. Conviene aclarar que el hecho de que las cifras diezmales de la diócesis de Santiago no registren la producción de patatas no introduce un sesgo apreciable en nuestros cálculos, porque a la altura de 1804 eran muy pocas las comarcas de la misma en las que su cultivo había alcanzado importancia. 
tación. Lo más característico de la explotación media de Orense es que con un notable nivel de producción de cereales $(47,85 \mathrm{hls}$.), del que casi un tercio corresponde ya al maiz, su producción per cápita tanto de vino como de castañas era la más elevada de las tres diócesis.

En Lugo las cifras son inferiores para todos los productos. La producción media de cereales, entre los que el centeno mantiene un acusado predominio ( $80 \%$ ), no alcanza los 43 hls., mientras que la de vino es muy inferior a la de las explotaciones orensanas, dado el escaso número de parroquias en que se cultivaba, que no llegaba al $15 \%$. En Orense, en cambio, más de la mitad de las explotaciones producía vino.

En la Galicia occidental, por su parte, el maiz representa más del $70 \%$ de los casi $60 \mathrm{hls}$. de cereales de media por explotación. La producción viticola alcanza niveles superiores a los de la explotación media de Lugo, pero inferiores a los de Orense, en consonancia con su posición intermedia en cuanto al número de parroquias productoras de vino (el $37,6 \%$ ).

\section{CUADRO 1}

Producto bruto de cereales, castañas, babas y vino en las diócesis de Lugo y Orense (años 1763-1765-1766) y Santiago (1804). Totales y medias por explotación en bectolitros

\begin{tabular}{|c|c|c|c|c|c|c|}
\hline & \multicolumn{2}{|c|}{ Orense } & \multicolumn{2}{|c|}{ Lugo } & \multicolumn{2}{|c|}{ Santiago } \\
\hline & Total & Media & Total & Media & Total & Media \\
\hline 1. Cereales & 25.073 & 47,85 & 47.111 & 42,83 & 61.281 & 59,84 \\
\hline 2. Cast.-Habas & 3.976 & 7,59 & 4.714 & 4,28 & 506 & 0,49 \\
\hline 1+2. $\mathrm{CCH}$ & 29.049 & 55,44 & 51.825 & 47,11 & 61.787 & 60,34 \\
\hline 3. Vino $\ldots \ldots \ldots$ & 15.166 & 28,94 & 4.003 & 3,64 & 9.881 & 9,65 \\
\hline 4. Total ......... & 44.215 & 84,38 & 55.828 & 50,75 & 71.668 & 69,99 \\
\hline
\end{tabular}

Es evidente que estas cifras medias por explotación referidas a grandes conjuntos territoriales no tienen por qué ajustarse a la realidad particular de cada comarca agraria. En la Galicia interior las explotaciones con volúmenes de producción superiores a la media, que en ocasiones rebasan los $100 \mathrm{hls}$., se sitúan o bien en las zonas de casi monocultivo vitícola, o bien en comarcas cerealeras de la zona central de la provincia de Orense, con cifras que superan los 80 hls. entre cereales, castañas y habas. En la Galicia occidental el $30 \%$ de 
las explotaciones superan el listón de los $100 \mathrm{hls.,} \mathrm{y} \mathrm{aunque} \mathrm{no} \mathrm{existen} \mathrm{prácti-}$ camente explotaciones con monocultivo viticola, las explotaciones mixtas cereal-vino también figuran entre las más productivas.

En lo que respecta a las explotaciones con cifras inferiores a la media el panorama es más confuso. Por todos lados, sea en la Galicia occidental o en la central y meridional, encontramos explotaciones con volúmenes de producción modestos, entre 30 y $50 \mathrm{hls}$. Donde son más abundantes es en la Galicia central y centro-oriental, en zonas donde las condiciones ecológicas impedian o dificultaban el cultivo de la viña y predominaba el cultivo del centeno en régimen de barbecho.

Si para determinar la producción agraria bruta de los mayores productores hemos utilizado cifras de origen decimal que, con todas sus limitaciones, son suficientemente fiables, a la hora de precisar el producto neto y el excedente tenemos que movernos en el terreno de los supuestos generalizadores y de hipótesis pendientes de confirmar empíricamente. El procedimiento que hemos empleado consiste en restar al producto bruto calculado anteriormente la simiente, la renta de la tierra y el diezmo, obteniendo así un producto neto en hectolitros que hemos transformado en unidades calóricas ${ }^{14}$. Si a esta cifra, que refleja el equivalente calórico de la producción a disposición de los miembros de la familia campesina, le restamos a su vez el consumo teórico medio necesario para la satisfacción de sus necesidades alimenticias, estaremos estimando el volumen de producción que la explotación puede comercializar o utilizar a su antojo sin comprometer su reproducción.

Veamos en primer lugar el caso de la Galicia interior. En el cuadro 2 puede apreciarse que el producto bruto medio anual ascendió a $61,6 \mathrm{hls}$. por explotación. El equivalente calórico del producto neto $(38,68 \mathrm{hls}$.) se situó en algo más de 18.600 calorias diarias por hogar, de las cuales casi un $9 \%$ fueron «calorias vacías», sin otros componentes nutritivos, proporcionadas por el vino. Esta aportación calórica fue suficiente para cubrir las necesidades de consumo de la familia típica, ya que al ser la dimensión media de los hogares de la muestra de 8,7 personas ${ }^{15}$, sus necesidades calóricas estarían, según nuestras estimaciones, en 13.500 calorías por día. Por consiguiente, una vez de-

14 La necesidad de simplificar nos ha obligado a no considerar las proteinas o los lípidos aportados por los alimentos. El procedimiento empleado para incluir en nuestros cálculos los nutrientes aportados por los alimentos de origen animal se detalla en el apéndice 1.

${ }^{15}$ Aunque es evidente que la composición y tamaño de las familias analizadas habrá variado desde los años en que se realiza el Catastro, ello no debe restar validez a unos cálculos que no se refieren a familias concretas, sino a un conjunto amplio de las mismas, de tal manera que el descenso en el número de componentes de unas se habrá compensado con el aumento de otras. 


\section{CUADRO 2}

Producto bruto $(P B)$, producto neto $(P N)$ y valor calórico del producto neto (CALNET) de cereales, castañas y babas (CCH) y de vino. Diócesis de Lugo y Orense, media trienal de 1763-1765-1766 (HL) (\%)

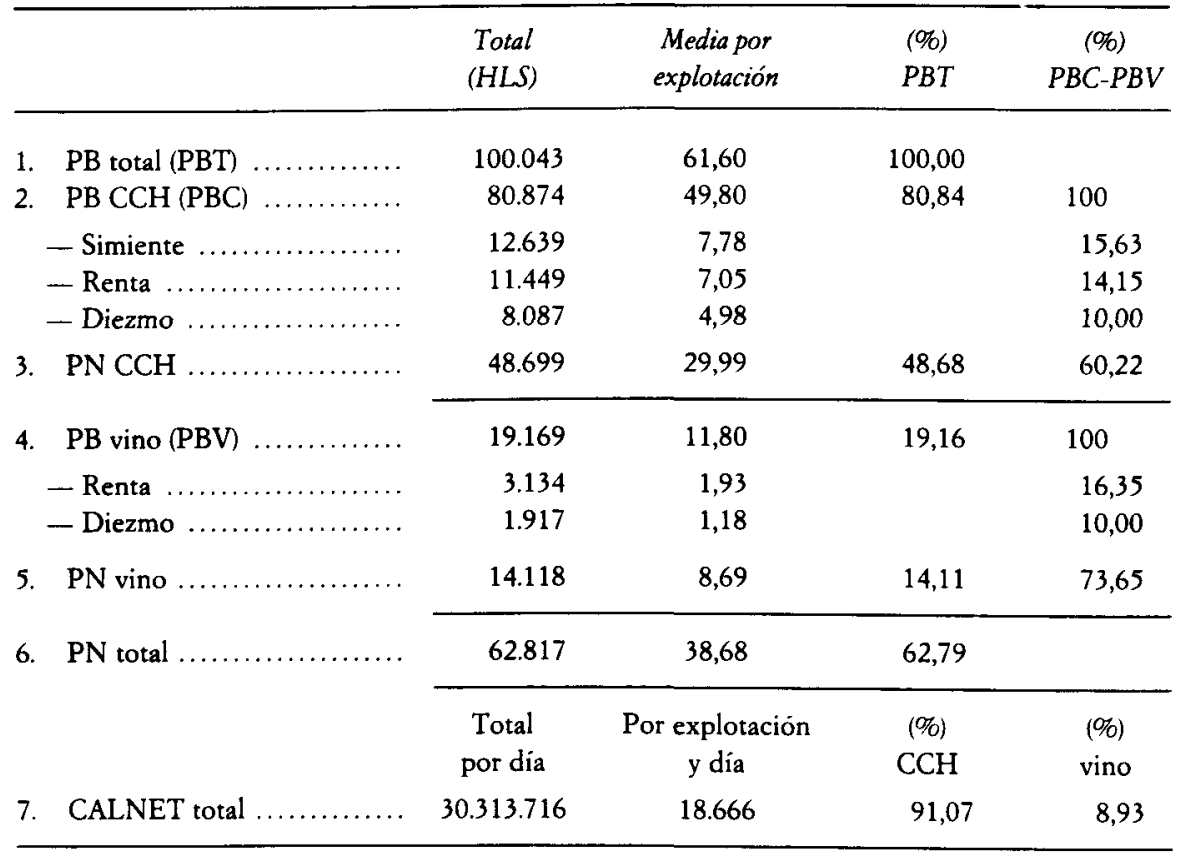

ducidos del producto bruto la simiente, el consumo familiar, la renta de la tierra y el diezmo, una explotación media dispondria de aproximadamente 5.200 calorías/día excedentarias, equivalentes a 10,7 hls. de su producción total.

El $73 \%$ de las explotaciones analizadas superó el mínimo de 13.500 calorías: un $40 \%$ obtuvo entre el 100 y el $150 \%$ de esa cifra, un $20 \%$ se situó entre el 150 y el $200 \%$ y sólo el $13 \%$ consiguió más del doble de lo necesario para satisfacer el consumo familiar. Las 440 explotaciones ( $27 \%$ del total) que no alcanzaron el producto neto suficiente para obtener 13.500 calorías se ubican en su mayor parte en las comarcas centrales y orientales de la provincia de Lugo (municipios de Friol, Guntin, Corgo, Castroverde, Baleira, Becerreá, Cervantes, Pedrafita, Láncara, Incio, Nogais, ...). Se trata de zonas en las que predominaba el cultivo del centeno, cuya producción fue muy baja en 1763, y en las que, por ser la importancia de la ganaderia superior a la media, cabe pensar 
que los alimentos de origen animal hubiesen aportado a la dieta bastante más de lo que hemos supuesto de modo general.

En cuanto a la capacidad de generar excedente de los mayores productores agrarios de la Galicia occidental (cuadro 3) puede apreciarse que los valores medios de las principales variables fueron más elevados en 1804 que los obtenidos cuarenta años antes por las explotaciones de la Galicia interior. Destaca el hecho de que el producto neto de cereales, castañas y habas se situó en 40 hls., superando en un tercio los casi $30 \mathrm{hls}$. de la Galicia interior. El nivel de disponibilidades calóricas per cápita fue también más elevado, duplicando casi las necesidades mínimas de un hogar medio. En este año concreto que, según todos los indicios, fue de buena cosecha tanto de cereales como de vino, las mayores explotaciones de la Galicia occidental obtuvieron, por término medio, una producción que permitió al $93 \%$ de las mismas superar el nivel calórico minimo necesario.

\section{CUADRO 3}

Producto bruto $(P B)$, producto neto $(P N)$ y valor calórico del producto neto (CALNET) de cereales, castañas y babas (CCH) y de vino.

Diócesis de Santiago. $1804(\mathrm{HL})(\%)$

\begin{tabular}{|c|c|c|c|c|}
\hline & $\begin{array}{c}\text { Total } \\
\text { (HLS) }\end{array}$ & $\begin{array}{l}\text { Media por } \\
\text { explotación }\end{array}$ & $\begin{array}{l}(\%) \\
P B T\end{array}$ & $\begin{array}{c}(\%) \\
P B C-P B V\end{array}$ \\
\hline 1. $\mathrm{PB}$ total $(\mathrm{PBT})$ & 71.669 & 69,99 & 100,00 & \\
\hline \multirow{4}{*}{ 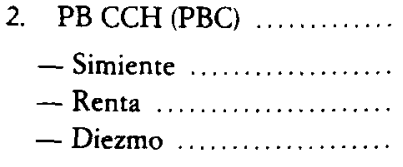 } & 61.787 & 60,34 & 86,21 & 100 \\
\hline & 5.736 & 5,60 & & 9,28 \\
\hline & 8.868 & 8,66 & & 14,35 \\
\hline & 6.179 & 6,03 & & 10,00 \\
\hline 3. $\mathrm{PN} \mathrm{CCH} \ldots \ldots$ & 41.004 & 40,04 & 57,20 & 66,36 \\
\hline 4. $\mathrm{PB}$ vino $(\mathrm{PBV})$ & 9.881 & 9,65 & 13,78 & 100 \\
\hline - Renta ................. & 1.230 & 1,20 & & 12,45 \\
\hline - Diezmo .................. & 988 & 0,96 & & 10,00 \\
\hline 5. $\mathrm{PN}$ vino $\ldots \ldots \ldots \ldots \ldots \ldots$ & 7.663 & 7,48 & 10,65 & 77,50 \\
\hline \multirow[t]{2}{*}{ 6. PN total } & 48.666 & 47,52 & 67,90 & \\
\hline & $\begin{array}{l}\text { Total } \\
\text { por dia }\end{array}$ & $\begin{array}{l}\text { Por familia } \\
\text { y dia }\end{array}$ & $\begin{array}{l}(\%) \\
\mathrm{CCH}\end{array}$ & $\begin{array}{l}(\%) \\
\text { vino }\end{array}$ \\
\hline 7. CALNET total & 26.910 .651 & 26.280 & 94,54 & 5,46 \\
\hline
\end{tabular}


En el cuadro 4 recogemos de forma resumida las diversas variables que han entrado en juego a lo largo de este trabajo. El excedente de una explotación de la Galicia interior no superó, por término medio, el $20 \%$ de su producto bruto. Con 10,7 hls, de superávit la familia superaba en 5.200 calorías/ dia sus necesidades alimenticias anuales, y podía alimentarse durante 5 meses más. En la Galicia occidental un año de buena cosecha permitió que ese excedente alcanzase el $33 \%$ del producto bruto, pero es muy probable que en un año agrario «normal» estuviese más cerca del 20 que del $30 \%$. En este caso, con la producción de un año y después de cubrir sus necesidades alimentarias, la familia dispuso de 23,11 hls., con los que obtuvo casi lo suficiente para alimentarse durante un año más (12.780 calorías/día).

\section{CUADRO 4}

Producto bruto, costes de reproducción y excedente de una "casa mayor diezmera» media de la Galicia interior y de la Galicia occidental (bls.) (\%)

\begin{tabular}{|c|c|c|c|c|c|}
\hline & & \multicolumn{2}{|c|}{ Lugo-Orense } & \multicolumn{2}{|c|}{ Santiago } \\
\hline & & Hls. & (\%) & Hls. & (\%) \\
\hline 1. & Producto bruto & 61,60 & 100 & 69,99 & 100 \\
\hline 2. & Simiente ........... & 7,78 & 12,63 & 5,60 & 8,00 \\
\hline 3. & Diezmo-Renta tierra & 15,14 & 24,58 & 16,86 & 24,09 \\
\hline 4. & Producto neto (PN) & 38,67 & 62,79 & 47,52 & 67,90 \\
\hline 5. & Calorias/Día PN ............... & $(18.666)$ & & $(26.280)$ & \\
\hline 6. & Consumo necesario $\ldots \ldots \ldots \ldots$ & 27,97 & 45,41 & 24,41 & 34,88 \\
\hline 7. & Excedente...$\ldots \ldots \ldots \ldots \ldots \ldots$ & 10,70 & 17,37 & 23,11 & 33,02 \\
\hline
\end{tabular}

Nota: Cifras medias del trienio 1763-1765-1766 para Lugo y Orense, y datos del año 1804 para Santiago.

\section{CONCLUSION}

Lo expuesto hasta aqui nos ha servido para precisar el volumen y la composición de la producción de las explotaciones que gestionan campesinos acomodados e hidalgos y para estimar las principales cargas y costes de producción a que debían hacer frente. Se trata de explotaciones que, salvo en las zonas de especialización viticola, diversifican su producción entre cereales de invierno y primavera, castañas, vino, lino y ganadería, y que, por otra parte, su- 
peran a las demás por su capacidad de autoabastecerse y obtener un excedente de forma regular. Estamos ya, pues, en condiciones de dar respuesta a las cuestiones que planteábamos al comienzo del trabajo.

Lo primero a destacar es que la evidencia empírica disponible apunta a que la mayor parte de los productores agrarios de la Galicia de mediados del xVIII estaban claramente por debajo de las explotaciones que hemos analizado, tanto en volumen de producción como en capacidad excedentaria. Las diferencias entre unos y otros eran señaladas, quizá con cierta exageración, por los curas del arciprestazgo de Barbeiros cuando en 1761 clasificaban según su capacidad de autoabastecimiento a los 1.438 vecinos de la comarca. Ciento veintiún vecinos eran calificados de «acomodados» porque nunca dejaban de obtener el fruto preciso para comer durante todo el año; 25 eran ude mediana conveniencia» porque lo hacían para 7 u 8 meses del año, y 1.292 eran «pobres» porque sólo cosechaban lo suficiente como para sostenerse durante 3 o 4 meses ${ }^{16}$. Y lo que hasta el momento sabemos acerca de los graves efectos de la crisis de subsistencias de 1768-69 encaja perfectamente con esta imagen de una mayoría de la población rural que estaba lejos de superar el nivel de subsistencia.

No parece, por consiguiente, descaminado sostener que en Galicia, al igual que en Asturias o Cantabria ${ }^{17}$, se crearon a lo largo de la Edad Moderna condiciones que favorecieron un proceso de diferenciación «hacia abajo» entre los productores agrarios, y que este proceso no tuvo como resultado que una minoría se alejase de los demás alcanzando niveles de producción claramente por encima del autoabastecimiento. Al contrario, fue el aumento del número de campesinos deficitarios y dedicados a múltiples actividades no propiamente agrarias lo que situó en la cúspide de los productores agrarios a un grupo que no dejaba de tener una situación precaria. Gran parte de los mayores productores eran incapaces de mantener un resultado excedentario cuando las oscila-

16 Archivo Histórico Diocesano de Santiago (AHDS), Serie General, leg. 265. Las descripciones acerca de las condiciones de vida de la población rural que hacen los curas de la diócesis de Orense a finales de la década de 1760 coinciden en destacar que son pocos los vecinos que obtienen un volumen de producción suficiente para cubrir las necesidades de consumo de sus familias. El cura de San Ciprián de Rouzos (Amoeiro) decía en 1769 que su parroquia estaba compuesta de 86 vecinos, «... entrando en este número unos ocho que están en casa solos, y sin vienes, y de los otros la mayor parte no les llega el fruto que cogen para pasar el año por abundante que sea». Y el de San Pedro de Ramirás (Ramirás) insistía en lo mismo: «..., i todos ellos por lo reducido de su cultibo, y no tener montes donde estenderse, a reserva de unos cuatro vecinos los demás no cogen pan para cuatro meses del año, i se balen de ir a Castilla y Portugal a trabajar y ganar la vida*. En San Salvador de Solbeira (Orense) de los 45 hogares de la parroquia «... ninguno llega a coger fruto para su sustento, despues de pagar diezmos y rentas, a escepzion de la Casa Diezmera, que posee mas vienes raices que cuasi la mitad de ellos». Archivo Histórico Diocesano de Orense (AHDO), Estadistica, leg. 7.5.3.

17 Dominguez y Lanza (1990 y 1991) han insistido en ello. 
ciones climáticas afectaban negativamente a las cosechas, de manera que los valores «medios» de excedente, que oscilaban entre 10 y 20 hectolitros al año y con los cuales la familia «tipo» podría alimentarse entre 5 y 12 meses más, no eran lo suficientemente elevados como para garantizar el consumo o el pago de la renta. Esto se aprecia con claridad en las cifras del cuadro 5, donde hemos calculado el excedente obtenido por las explotaciones de la Galicia interior en un año de mala cosecha de cereales y de cosecha media de vino (1763) y en otro de buena cosecha de ambos productos (1765).

\section{CUADRO 5}

Producto bruto, costes de reproducción y excedente de una «casa mayor diezmera» media de la Galicia interior en los años 1763 y 1765 (bls.)(\%)

\begin{tabular}{|c|c|c|c|c|c|c|c|}
\hline & & \multicolumn{2}{|l|}{$1763-65$} & \multicolumn{2}{|l|}{1763} & \multirow{2}{*}{$\frac{1765}{H l s .}$} & \multirow{2}{*}{$\frac{\text { Media }}{(\%)}$} \\
\hline & & $H l s$ & (\%) & Hls. & (\%) & & \\
\hline 1. & P. bruto $\mathrm{CCH}$. & 38,23 & & 53,81 & & 46,02 & \\
\hline 2. & P. bruto vino .. & 10,56 & & 15,09 & & 12,82 & \\
\hline 3. & P. bruto total .. & 48,79 & 100 & 68,90 & 100 & 58,84 & 100 \\
\hline 4. & Simiente ........ & 7,78 & 15,94 & 7,78 & 11,29 & 7,78 & 13,22 \\
\hline \multirow[t]{2}{*}{5.} & Diezmo-Renta & & & & & & \\
\hline & de la tierra .... & 13,89 & 28,47 & 15,90 & 23,08 & 14,89 & 25,30 \\
\hline 6. & P. neto total ... & 27,12 & 55,58 & 45,22 & 65,63 & 36,17 & 61,47 \\
\hline 7. & CALNET dia & $(12.655)$ & & (21.244) & & $(16.950)$ & \\
\hline 8. & Cons. neces. ... & 28,93 & 59,29 & 28,74 & 41,71 & 28,81 & 48,96 \\
\hline 9. & Excedente ..... & $-1,81$ & $-3,71$ & 16,48 & 23,92 & 7,36 & 12,50 \\
\hline
\end{tabular}

Si en 1765 el excedente alcanza el $24 \%$ del producto bruto, dos años antes habia sido negativo en casi un $4 \%$. El análisis de las disponibilidades calóricas no puede ser más elocuente. La baja cosecha de centeno provocó que en 1763 un conjunto considerable de explotaciones quedase por debajo de las necesidades calóricas mínimas, y por eso la media general fue de únicamente 12.655 calorias por explotación. El 1764 volvió a ser un mal año de centeno, y es probable que la situación deficitaria se hubiese repetido. Por el contrario, los años 1765 y 1766 permitieron que la disponibilidad calórica neta por explotación fuera de 21.244 y 21.342 calorías/dia, respectivamente.

No cabe duda de que estamos, dentro del conjunto de los productores agrarios, ante los que mejor pueden sobrellevar un mal año agrario, o los que 
mayor partido pueden sacar de la escasez. Aunque el consumo familiar no estuviese, año tras año, garantizado, son los que aprovechan las oscilaciones mensuales o anuales de los precios y venden cuando están altos. Son también los que, avalados por su patrimonio, tienen una mayor capacidad de endeudamiento, o los que pueden recurrir al ahorro de años anteriores para salir de los apuros. $\mathrm{Y}$ son, igualmente, los que más se benefician del proceso inflacionario que tiene lugar hasta 1817. Sin embargo, no deja de ser significativo que una parte considerable de los mayores productores experimente un déficit cuando falla la cosecha de algún producto importante. El hecho de que hayamos constatado que con cierta frecuencia se dedican a actividades extraagrarias como la manufactura, la arriería, o el comercio al por menor, pone de manifiesto las dificultades con las que se encontraban para mantener un nivel de vida holgado a través del trabajo de la tierra.

Los estratos inferiores del campesinado estaban más expuestos a las crisis de subsistencias y participaban en los circuitos mercantiles desde una posición de suma debilidad. Debian comprar una parte de los alimentos o el ganado que precisaban, o debian vender su fuerza de trabajo, o se veian obligados a endeudarse y pagar en dinero, a precios de «soldadura», las rentas estipuladas en especie que no podian satisfacer en años de mala cosecha. La explicación de que, pese a este oscuro panorama, las crisis demogräficas fuesen en Galicia relativamente moderadas en relación a otras zonas peninsulares, y la esperanza de vida superior a la de la mayoria de las restantes regiones españolas ${ }^{18}$, reside en la diversificada estructura de cultivos de las explotaciones y en la existencia de múltiples formas de obtener ingresos complementarios que, aunque por separado tuviesen escasa relevancia, facilitaron la subsistencia campesina. Era precisamente esta necesidad de complementar unos ingresos agrarios insuficientes la que empujaba a una parte apreciable de cultivadores a participar tanto en las fuertes migraciones temporales registradas en Galicia en este periodo como en todo tipo de actividades complementarias de la propiamente agrícola ${ }^{19}$.

La superior posición de los mayores productores queda, pues, resaltada si dirigimos nuestra mirada hacia abajo dentro del campesinado. Pero si, por el contrario, comparamos su volumen de ingresos y su capacidad de obtención de excedente con las de los perceptores de rentas y diezmos, apreciaremos lo erróneo que sería sobrevalorar el papel que juegan en la sociedad rural. La mayoría de las explotaciones alcanzan cifras de producción que no son compa-

18 Dopico y Rowland (1990), p. 601.

19 Cuestion sobre la que ya Carmona (1986) habia llamado la atención. 
rables a las de los frutos percibidos por el dueño de un pazo, el titular de un mayorazgo, un prior o un párroco. Y mucho menos al nivel de ingresos de un monasterio importante como el de San Martín de Santiago, que cifraba en 1742 sus rentas y diezmos en más de 12.000 hls., es decir, tanto como el excedente obtenido por 1.120 de los mayores productores de Lugo y Orense ${ }^{20}$. El volumen de rentas forales de diversas casas hidalgas que nos son conocidas superaba con frecuencia los 150 hls. y llegaba a los 1.000 hls., y estas cifras eran rebasadas claramente por muchos prioratos monásticos. Incluso una parte apreciable de los curas alcanzaban, gracias a la percepción de diezmos, niveles de ingresos por encima de los volúmenes de producto bruto de las explotaciones analizadas ${ }^{21}$. Y no olvidemos que el ratio ingreso bruto-ingreso neto era siempre más favorable para rentistas y beneficiarios de diezmos que para cultivadores.

La comparación con otras regiones españolas en las que el proceso de producción agraria estaba en manos de pequeñas o medianas explotaciones, y para las que existen datos del diezmo pagado por las casas excusadas, sugiere que en otras zonas no se produjo un proceso semejante de diferenciación «hacia abajom, o que, si tal proceso tuvo lugar, no fue incompatible con la existencia de una elite de explotaciones con volúmenes de producción muy por encima de los detectados en Galicia, Asturias o Cantabria. No nos ha sido posible aplicar a otras regiones la metodología desarrollada en este trabajo, y nos contentaremos con presentar las cifras del producto bruto obtenido por los mayores diezmeros de algunas diócesis españolas. Por supuesto, la comparación con las regiones donde existían grandes explotaciones carece de sentido ${ }^{22}$, y lo lógico es tomar como referencia aquellas donde sabemos que el tipo de explotación que protagoniza el proceso productivo era similar al que predominaba en Galicia. En el cuadro 10 presentamos una muestra lo suficientemente amplia como para percibir las diferencias entre regiones. Pese a no tener la certidumbre de estar ante niveles medios de producción, y pese a no poder precisar el producto neto, la impresión es que en zonas como La Rioja o Cataluña, y más

20 AHDS, Fondo San Martin, carp. 66.

21 Villares (1982, pp. 50-51) ofrece cifras al respecto: a mediados del xvin el priorato de Asma percibía $1.250 \mathrm{hls}$. de cereal y 336 de vino; la casa hidalga de Lagariños, 538 y 200 , respectivamente; $y$ otras casas menos importantes superaban los 150 hls. Barreiro $(1990$, p. 25) señala que el mayorazgo de Raindo andaba en torno a los $750 \mathrm{hls}$. de cereales y 187 de vino.

22 Es fácil encontrar en las diócesis de Cádiz o de Sevilla casas excusadas que alcanzan cosechas de trigo superiores a 2.000 ó $3.000 \mathrm{hls}$., y que obtienen además producciones importantes de otros cereales, vino, aceite o ganado. Así, por ejemplo, en 1764 el mayor diezmero de Osuna, D. Andrés Tamayo y Barona, pagó 563 fanegas de trigo y 550 de cebada, y el de Santa Maria de Carmona, D. Antonio Berrugo, 502,5 fanegas de trigo y 140 de cebada. AGS, DGR 2.", leg. 647. 


\section{CUADRO 6}

Producto bruto de las casas diezmeras de diferentes diócesis españolas en el periodo 17631775. Cereales, castañas y leguminosas (a), vino (b), cereales, castañas, leguminosas y vino, sin incluir cebada, avena y otras producciones destinadas al ganado (c). $(\mathrm{Hls} .)^{23}$

\begin{tabular}{|c|c|c|c|c|c|c|c|}
\hline & Núm. & Total & Total & & Media & blotación & \\
\hline & casas & (a) & (b) & (a) & (b) & $(a+b)$ & (c) \\
\hline Cataluña & & & & & & & \\
\hline Barcelona (3) .... & 217 & 24.342 & 11.526 & 112,17 & 53,11 & 165,29 & 148,16 \\
\hline Barcelona (4) .... & 211 & 23.707 & 13.559 & 112,35 & 64,26 & 176,62 & 162,45 \\
\hline Tarragona (1) ... & 133 & 14.845 & 6.226 & 111,61 & 46,81 & 158,40 & 125,48 \\
\hline Tarragona (2) $\ldots$ & 129 & 14.023 & 8.292 & 108,70 & 64,28 & 173,00 & 139,20 \\
\hline Vich (3) ......... & 246 & 31.720 & 3.713 & 129,00 & 15,04 & 144,04 & 127,30 \\
\hline Vich (5) $\ldots \ldots \ldots$ & 231 & 32.499 & 5.152 & 140,69 & 22,30 & 163,00 & 145,70 \\
\hline Solsona (4) ..... & 165 & 18.894 & 1.791 & 114,51 & 10,86 & 125,37 & 106,76 \\
\hline Lérida (1) ....... & 122 & 13.621 & 762 & 111,65 & 6,25 & 117,90 & 79,75 \\
\hline Lérida (2). & 122 & 10.829 & 1.134 & 88,76 & 9,29 & 98,06 & 75,92 \\
\hline Lérida (3) ....... & 121 & 12.817 & 1.166 & 105,92 & 9,64 & 115,56 & 85,75 \\
\hline Tortosa $(3) \ldots \ldots$ & 86 & 4.697 & 2.959 & 54,62 & 34,40 & 89,02 & 80,72 \\
\hline Tortosa $(4) \ldots \ldots$ & 84 & 4.837 & 2.433 & 57,58 & 28,96 & 86,54 & 78,08 \\
\hline Rioja, Navarra y Pai & Vasco & & & & & & \\
\hline Calahorra (1) .... & 930 & 96.069 & 8.299 & 103,30 & 8,92 & 112,22 & 77,73 \\
\hline Calahorra (2) .... & 917 & 99.791 & 16.359 & 108,80 & 17,84 & 126,66 & 89,75 \\
\hline Calahorra (3) .... & 717 & 83.534 & 13.287 & 116,59 & 18,53 & 135,04 & 90,83 \\
\hline Pamplona (1) .... & 872 & 108.272 & 7.654 & 124,16 & 8,78 & 132,94 & 96,55 \\
\hline Pamplona (2) .... & 872 & 104.731 & 6.626 & 120,10 & 7,60 & 127,70 & 96,40 \\
\hline Pamplona (3) .... & 872 & 121.173 & 6.114 & 138,96 & 7,01 & 145,97 & 116,16 \\
\hline Castilla y León & & & & & & & \\
\hline León (3) ... & 941 & 121.483 & 2.253 & 129,10 & 2,39 & 131,49 & 92,05 \\
\hline León $(4) \ldots \ldots \ldots$ & 949 & 135.669 & 6.285 & 142,96 & 6,62 & 149,58 & 106,00 \\
\hline León (5) .... & 861 & 116.705 & 5.613 & 135,55 & 6,52 & 142,07 & 103,25 \\
\hline Zamora (4) & 289 & 79.676 & - & 275,69 & - & 275,69 & 201,28 \\
\hline Zamora (5) ...... & 286 & 63.448 & - & 221,84 & - & 221,84 & 153,00 \\
\hline Salamanca (4) ... & 240 & 107.737 & - & 448,90 & - & 448,90 & 372,10 \\
\hline Salamanca (5) ... & 218 & 86.908 & - & 398,66 & - & 398,66 & 316,94 \\
\hline Asturias y Cantabria & & & & & & & \\
\hline Oviedo (4) & 374 & 24.340 & SD & 65,08 & SD & 65.08 & 56.46 \\
\hline Santander (4) .... & 500 & 16.254 & 1.431 & 32,51 & 2,86 & 35,37 & 34,89 \\
\hline Galicia & & & & & & & \\
\hline Orense (6) & 524 & 29.049 & 15.166 & 55,44 & 28,94 & $\begin{array}{l}84,38 \\
50,75\end{array}$ & $\begin{array}{l}84,38 \\
5075\end{array}$ \\
\hline Lugo (6) .......... & 1.100 & 51.825 & 4.003 & 47,11 & 3,64 & $\begin{array}{l}50,75 \\
69,99\end{array}$ & $\begin{array}{l}30,3 \\
69,99\end{array}$ \\
\hline Santiago $(7) \ldots \ldots$ & 1.024 & 61.787 & 9.881 & 60,34 & 9,65 & & \\
\hline
\end{tabular}

Nota: (1), año 1763; (2), 1764; (3), 1765; (4), 1766; (5), 1775; (6), media 1763-1765-1766; (7), 1804. FUENTES: AGS, DGR, 2., legs. 640-647-648-649.

23 Los datos que figuran en este cuadro tienen un carácter aproximativo por cuanto hemos tenido que simplificar a la hora de realizar el paso a hectolitros, y tampoco hemos considerado producciones como la lana, las crias, las fibras textiles, el aceite, etc. A la fanega castellana, medida habitual en que se ofrecen las cuentas, le hemos asignado $0,555 \mathrm{hls}$., y a la arroba y la cántara de vino $0,13 \mathrm{hls}$. Para la carga de uvas y el cántaro de vino en las cuentas de Pamplona y Calahorra tomamos los valores que asigna 
todavia en Zamora o Salamanca, una parte apreciable de los mayores productores sobrepasan con claridad los volúmenes de producción obtenidos por los de Galicia, Asturias, Cantabria o el País Vasco ${ }^{24}$, aunque esta diferencia se acorte si excluimos del cómputo la producción no destinada al consumo humano.

La constatación de estas diferencias avala la hipótesis de que en las regiones citadas, a diferencia de lo que sucedía en Galicia o la cornisa cantábrica, existian condiciones que facilitaban la explotación directa de la tierra a mayor escala, y que el proceso de diferenciación habia hecho mayor la distancia entre los grandes y los pequeños productores y habia colocado en la cima a una elite de explotaciones claramente excedentarias.

No es fácil precisar la incidencia que haya podido tener en la evolución de la agricultura de cada región a lo largo del XIX el hecho de que en algunas existiese una elite de explotaciones con volúmenes de producción y excedente relativamente altos y en otras no. Ni estamos aquí en condiciones de explicar las causas de tales diferencias. En cualquier caso, los estudios realizados en diversos países y para diversos períodos destacan que cuanto mayor sea el nivel de ingresos y la capacidad excedentaria de las explotaciones agrarias campesinas, mayor es también su disposición a asumir riesgos en sus decisiones sobre el proceso productivo. Es decir, mayor será, ceteris paribus, su propensión a invertir en la ampliación y mejora de los medios de producción, o a adoptar sistemas de cultivo orientados a maximizar el producto o el volumen de ingresos de la explotación (dedicando, por ejemplo, más superficie a cultivos comerciales en sustitución de los destinados al consumo familiar, o a plantas no comestibles en lugar de las comestibles, o a nuevas variedades de simientes de rendimientos altos pero variables, en sustitución de las tradicionales). Ya Scott habia destacado que los comportamientos tendentes a «minimizar la probabilidad de un desastre» caracterizaban no sólo a los campesinos más pobres, sino también a muchos de los llamados campesinos medios, y que este argumento no era probablemente aplicable «... a los campesinos con ingresos altos, tierra abundante, familias pequeñas, cosechas poco variables y oportunidades de empleo alternativas» 25 . Haciendo un balance de los re-

Floristán (1982, p. 16), 0,5885 y 0,1177 hls. respectivamente. Hemos contabilizado únicamente a los diezmeros que producian alguno de los productos considerados (cereales, leguminosas y vino), y no hemos incluido a aquellos que obtenian cantidades muy pequeñas de los mismos en parroquias rurales o despoblados.

24 Las cifras correspondientes al conjunto de la diócesis de Calahorra esconden realidades comarcales diferentes, como seguramente sucede en las restantes diócesis. El producto bruto de cereales y vino destinados al consumo humano de los partidos de Guipúzcoa y Vizcaya en los años 1763-64-65 estuvo entre 50 y 60 hls., cifras muy próximas a las de Galicia, mientras que en los partidos de Calahorra y La Calzada, en tierras riojanas, sobrepasó los $140 \mathrm{hls.}$

25 Scott (1976), pp. 15-26. 
sultados obtenidos en diversos estudios, Ellis argumentaba que la aversión al riesgo «... desciende a medida que aumentan la riqueza o el ingreso. Las explotaciones con mayor nivel de ingresos o de riqueza estān más capacitadas para hacer frente a las pérdidas que pudiesen resultar de la toma de decisiones arriesgadas. De ello se deduce que los agricultores con mayor nivel de ingresos deberian ser más eficientes, estar más preparados para especializarse en cultivos comerciales y ser más propensos a innovar. Es también más fácil que estén mejor informados y tengan mayor acceso al crédito» 26 .

De acuerdo con esto, el factor «aversión al riesgo» habria jugado en Galicia un papel que no puede ser despreciado. Es sabido que los agricultores gallegos recibieron desde mediados del XIX estímulos poderosos hacia la comercialización de una parte cada vez mayor de su producción (el nuevo sistema fiscal), o hacia una especialización ganadera (la presión de la demanda inglesa y, más tarde, la española), para la que Galicia contaba con ventajas comparativas. Si, pese a ello, la evolución de su agricultura durante buena parte del XIX siguió basándose en la intensificación de la producción aplicando más horas de trabajo por hectárea pero sin incrementar la productividad del trabajo, en la extensión de cultivos como el maíz y la patata con el fin de garantizar el autoconsumo, y en la diversificación de la producción para minimizar riesgos, fue por la persistencia de obstáculos difíciles de franquear. Al mantenimiento del sistema foral y al reducido tamaño de las explotaciones se añadia, tal como señalaba Carmona ${ }^{27}$, la ausencia de núcleos urbanos de importancia, las dificultades de transporte y la propia debilidad de la demanda española, que bloquearon «... la expansión de la ganadería vacuna o la mejora de rotaciones en un sentido "new farming"». Si algo hemos podido verificar en el presente trabajo es precisamente que, entre las rigideces que dificultaban las transformaciones agrarias, debemos conceder un papel destacado a la escasa presencia de explotaciones que por su dimensión o capacidad de acumulación hubiesen podido introducir sin excesivo riesgo las innovaciones necesarias para la modernización del sector agrario gallego en el siglo XIX.

26 Ellis (1988), pp. 93-96. En lo que respecta al caso gallego, hay que señalar que Carmona (1990, p. 54) ha llamado recientemente la atención sobre la importancia del tema.

27 Carmona (1990), pp. 46-55. 


\section{APENDICE 1. MEDIDAS, COEFICIENTES DE CONVERSION DE LITROS EN KILOGRAMOS Y DE KILOGRAMOS EN CALORIAS}

Un problema metodológico universal de los estudios sobre producción agraria en períodos como el que aquí se aborda es el de la transformación de las medidas tradicionales en medidas estándar de capacidad o peso. Las fuentes que hemos manejado ofrecen todos los datos de cereales, castañas, habas, garbanzos, nueces, etc., en ferrados y fanegas, y los de vino en moyos, cántaras y arrobas. Para su transformación en litros hemos utilizado las tablas de conversión elaboradas por Fernández Justo ${ }^{28}$ para cada uno de los municipios gallegos. Lo que reviste mayor importancia de este ajuste, además de las diferencias que se observan entre unas comarcas y otras, es la distinción entre los ferrados «colmados», utilizados mayoritariamente para la medición del maíz y que tienen entre 18 y 20 litros, y los ferrados «rasos», para el resto de los cereales y las castañas, que no suelen pasar de los 15-16 litros.

El resto de los productos es contabilizado en medidas para las que es más dificil encontrar un equivalente en litros o gramos, como es el caso de los afusales de lino o los cuartillos y libras de manteca, y en estos casos tomamos como criterio homogeneizador su valor en dinero a precios corrientes, proporcionados por las propias fuentes.

Una vez establecida la equivalencia en litros, hemos reducido a kgs. los distintos cereales, las castañas y las habas, suponiendo que un litro pesa aproximadamente $0,75 \mathrm{~kg}$. El siguiente paso ha sido atribuir un valor calórico a cada producto, para lo que hemos tomado los coeficientes ofrecidos por J. Simpson: 3.420 calorias para el kg. de harina de trigo, 2.800 para la de centeno, 3.180 para la de maiz, 2.800 para la de mijo menudo y otro tanto para el $\mathrm{kg}$. de habas (asumiendo el valor que atribuye Simpson a la categoria «Otros cereales»), y 700 calorías para el litro de vino ${ }^{29}$. Para el $\mathrm{kg}$. de castaña verde, dato que este autor no aporta, el valor escogido ha sido de 2.000 calorías ${ }^{30}$. Para, a su vez, transformar el kg. de grano en $\mathrm{kg}$. de harina hemos supuesto, tal como suele hacerse, que de cada kg. de grano se obtiene $0,75 \mathrm{~kg}$. de harina, transformación que aplicamos únicamente al trigo y no al resto de los cereales por ser práctica habitual en Galicia la elaboración de pan (de maíz o centeno) sin retirar el salvado, lo que sí se hacía con el trigo.

\footnotetext{
28 Fernández, M. (1986).

29 Simpson, J. (1989), pp. 366-367 y 384.

30 Roselló, J. (Coord.) (1989), p. 240.
} 
No resulta fácil precisar una cifra de necesidades calóricas mínimas por persona. Simpson cita estudios realizados en Estados Unidos que cifran el consumo diario de un hombre de referencia (varón adulto con actividad física media) en 2.400 calorías. Shammas cita asimismo estudios de expertos en nutrición que elevan a 2.700 calorias esa cifra. Por su parte, C. Lis y H. Soly prefieren tomar como referencia las 2.000 calorías, aunque insisten en que esta cantidad es suficiente sólo cuando va acompañada de una dieta equilibrada. Y este mismo valor es el que Livi-Bacci considera más adecuado ${ }^{31}$. Entre el abanico de posibilidades de estimación de las necesidades alimenticias de un varón adulto que tiene en su extremo inferior las 2.000 calorías diarias y en el superior 3.000 , hemos optado por utilizar en nuestra argumentación un valor intermedio, 2.500 .

Hecho esto, hay que resolver otra cuestión: ¿qué necesidades calóricas atribuir a una familia típica de las que estamos considerando? El primer paso, según la metodologia habitualmente empleada, consiste en determinar su composición por edades y sexo, y ponderar el requerimiento calórico de los niños y de las mujeres adultas en relación a un varón adulto, considerado como unidad de consumo estándar. De las ponderaciones utilizadas por diversos autores hemos seleccionado las de Essemyr ${ }^{32}$, que cifra las necesidades calóricas de las mujeres adultas y de los niños en el 80 y el $60 \%$, respectivamente, de las del varón adulto. Como el Catastro de Ensenada no especifica la edad de las hijas ni la de las criadas, hemos considerado que la familia media de la muestra que utilizamos, con 8,7 componentes, tenía el mismo porcentaje de menores de 16 años que tenia el conjunto de la población gallega según el Censo de Floridablanca (el 35,11\%). Resultan asi unas necesidades calóricas diarias minimas equivalentes a las de 6 varones adultos, es decir, de 15.000 calorías.

El principal defecto del procedimiento anterior es que no tiene en cuenta el rendimiento calórico que las familias obtenían a partir de los productos ganaderos. Si el cálculo del valor calórico de los alimentos de origen vegetal puede realizarse con un mínimo de garantías de precisión, ya que para estos productos los datos diezmales son fiables y nos dan a conocer el volumen exacto de lo recaudado, no sucede lo mismo con la producción ganadera por dos razones. En primer lugar, porque el producto de la ganadería es subestimado por el diezmo. Y en segundo lugar, porque es muy difícil determinar la cantidad de carne que podría obtenerse de un lechón, un cordero o un carnero, o la cantidad de manteca que producía una vaca. La mejor manera de resolver este problema, sin aumentar el margen de error

31 Simpson, J. (1989), p. 368; Shammas, C. (1984), p. 257; Lis, C. y Soly, H. (1977), p. 478; LiviBacci, M. (1988), p. 50.

32 Essemyr, M. (1986), pp. 81-83. 
de nuestros cálculos, consiste en rebajar de las necesidades calóricas totales de la familia la parte de calorias que podría obtener a partir de los alimentos de origen animal. Lo que nos ha parecido más razonable es suponer que el porcentaje de calorías de origen animal de la dieta está en torno al $10 \%$, cifra menor que el 16,7\% que Toutain estima para la Francia del Antiguo Régimen, pero muy semejante a la que Simpson obtiene para la España de principios del xx ${ }^{33}$. La estimación de Toutain nos parece excesiva en nuestro caso porque hay que tener en cuenta que una parte no pequeña de la producción ganadera de las familias estudiadas era vendida para obtener numerario con el que adquirir bienes o pagar impuestos, y no entraba por tanto en la alimentación cotidiana. Consideraremos, pues, que de las 15.000 calorías diarias necesarias para abastecer a una familia tipo, 1.500 son cubiertas por los alimentos de origen animal.

\section{LA DETERMINACION DEL PRODUCTO BRUTO Y DEL PRODUCTO NETO. SUPUESTOS SOBRE LOS COEFICIENTES SIMIENTE-PRODUCTO Y ESTIMACION DEL VOLUMEN DE LA RENTA DE LA TIERRA}

Una vez justificada la no inclusión en el «haber» del aporte calórico de los alimentos de origen animal, debemos probar que las cifras de producto bruto correspondientes a los años 1763-65-66 permiten obtener una media representativa del nivel «normal» de producción de las explotaciones analizadas. En el caso de Orense, hemos contrastado esta media trienal con la media del decenio para el que disponemos de cifras del excusado. La coincidencia entre ambas medias es total para cereales, castañas y habas, y sólo en la producción de vino detectamos una infraestimación del $2 \%$. Para la diócesis de Lugo, los únicos datos que poseemos son los del cuatrienio 1763-66, y de su comparación con nuestra media resulta que ésta supone el $104 \%$ de la producción de cereales, castañas y habas, y el $103 \%$ de la producción de vino.

Los mismos resultados se obtienen si acudimos a las cifras de producción reflejadas por algunas contabilidades monásticas, en este caso los ingresos por diezmos y rentas proporcionales a la cosecha en las comarcas de Monfero (al norte de la provincia de La Coruña) y Oseira (al noroeste de la de Orense).

La evolución de los precios confirma asimismo la representatividad del trienio seleccionado. Los precios de venta que los prioratos de la Galicia interior consignan para centeno y vino experimentan, en sentido inverso, las mismas tendencias

3) Simpson (1989, pp. 366-367), Toutain (1971, p. 1977). 


\section{CUADRO 6.1}

Producto bruto de las «casas diezmeras» de las diócesis de Orense y Lugo. Cereales, castañas y babas (CCH) (ferrados), y vino (moyos en Orense, y cäntaras en Lugo)

\begin{tabular}{lrrrrr}
\hline Orense & Año & CCH & Indice & Vino & Indice \\
\hline & 1763 & 119.018 & 74 & 8.101 & 87 \\
& 1765 & 172.751 & 107 & 11.956 & 128 \\
& 1766 & 192.790 & 120 & 7.368 & 79 \\
& 1775 & 157.230 & 98 & 10.250 & 110 \\
& 1776 & 149.550 & 93 & 10.070 & 108 \\
& 1777 & 164.800 & 103 & 7.310 & 78 \\
& 1778 & 184.525 & 115 & 10.480 & 112 \\
& 1779 & 131.280 & 82 & 10.695 & 114 \\
& 1780 & 172.430 & 107 & 8.655 & 93 \\
Media decenio & 1781 & 162.840 & 101 & 8.535 & 91 \\
Media trienio 1763-65-66 & & & & & \\
Lugo & & 160.722 & 100 & 9.342 & 100 \\
& 161.520 & 100 & 9.142 & 98 \\
& 1763 & 262.745 & 82 & 20.240 & 95 \\
& 1764 & 279.087 & 87 & 19.560 & 91 \\
& 1765 & 363.870 & 114 & 28.380 & 133 \\
Media 1763-1766 & 1766 & 374.900 & 117 & 17.460 & 82 \\
Media trienio 1763-65-66 & & & & & \\
& & 320.150 & 100 & 21.410 & 100 \\
& & 333.838 & 104 & 22.027 & 103 \\
\hline
\end{tabular}

FUENTES: AGS, DGR, 2." R., legs. 640, 647, 648, 649.

anuales que la producción reflejada por el excusado y con una intensidad semejante. En prácticamente todos los casos el precio del centeno en los años 1763 y 1764 supera en un 20-30\% el precio medio del cuatrienio 1763-66, y, viceversa, es en los años 1765 y 1766 cuando cae en proporciones semejantes. En lo que respecta al vino también se detecta un movimiento inverso al de la producción: precios ligeramente superiores a la media en 1763 y 1764 , descenso apreciable en 1765 , y nueva subida, superior a las anteriores, en $1766^{34}$.

Menos representativas son las cifras de la cosecha de 1804 correspondientes a la diócesis de Santiago, únicas disponibles para la mitad occidental de Galicia. A

${ }^{44}$ Estas comprobaciones las hemos realizado a partir de las contabilidades de los prioratos de Sobrado de Trives, Chouzán (Carballedo), Oleiros (Carballedo), Castro de Rei (Paradela), Salto (Rodeiro), Arrabaldo (Orense), Banga (Carballiño) y del monasterio de San Clodio (Leiro). 


\section{CUADRO 7}

Diezmos, cuartos y quintos de cereales percibidos por el monasterio de Monfero (1) y el priorato de Labrada (Guitiriz) (2), y diezmos de centeno percibidos por el monasterio de Oseira y sus prioratos de Coiras (Piñor) y Longos (S. C. de Cea)

(3). Fanegas

\begin{tabular}{lrrrrrr}
\hline & $(1)$ & Indice & \multicolumn{1}{c}{$(2)$} & Indice & (3) & Indice \\
\hline $1763 \ldots \ldots \ldots \ldots \ldots$ & 827 & 78 & 953 & 72 & 439 & 67 \\
$1764 \ldots \ldots \ldots \ldots \ldots$ & 966 & 91 & 1.211 & 91 & 665 & 101 \\
$1765 \ldots \ldots \ldots \ldots \ldots$ & 1.115 & 105 & 1.364 & 103 & 797 & 121 \\
$1766 \ldots \ldots \ldots \ldots \ldots$ & 1.351 & 127 & 1.793 & 135 & 729 & 111 \\
Media $1763-66 \ldots \ldots$ & 1.065 & 100 & 1.330 & 100 & 657 & 100 \\
Media trienio ....... & 1.098 & 103 & 1.370 & 103 & 655 & 100 \\
\hline
\end{tabular}

Fuentes: Archivo Histórico del Reino de Galicia (AHRG), Monasterios, Cajas 348 y 450; Archivo Histórico Provincial de Orense (AHPO), libros clero, 613, 620 y 628.

través de fuentes de producción y precios hemos podido comprobar que se trató de un año claramente superior a los nueve que lo precedieron gracias a una buena cosecha de maiz. Asi se deduce de los indices de producción de cereales obtenidos a partir de los diezmos y rentas proporcionales percibidos por varios monasterios y prioratos del norte de la diócesis, asi como de las estimaciones de la producción de cereales ofrecidas por los curas de 70 parroquias distribuidas por todo el territorio de la misma.

En todas las series se detectan con nitidez las malas cosechas de 1800 y $1803, \mathrm{y}$ se comprueba asimismo que la de 1804 fue claramente superior a la media debido a la buena cosecha de maíz. Las respuestas de los curas al citado Interrogatorio de 1804 destacan tal circunstancia: el de Soaserra (Cabanas) afirmaba que hacia «... cuarenta años que desta semilla de maíz no se cogió año por año tanta como el presente»; el de Cira (Silleda) que «... de este presente de 1804 asoma una buena cosecha de maíz»; y el de Toba (Cee) que «... la cosecha de trigo y zenteno del presente año fue escasa; y la de maíz ofreze buena».

$\mathrm{Si}$, por último, examinamos las series de precios de venta de distintos prioratos observaremos que los correspondientes a 1804 están siempre entre los más bajos del período 1795-1807.

Otra de las cuestiones metodológicas que requiere aclaración especial es la de los criterios a seguir para calcular el producto neto a disposición del cultivador, que hemos obtenido deduciendo del producto bruto la simiente, la renta de la tierra y el diezmo. De las variables que acabamos de citar sólo una nos es conocida de for- 


\section{CUADRO 8}

Indices de producción de cereales en diversas comarcas de Galicia occidental. Media 1795-1807-100

\begin{tabular}{|c|c|c|c|c|c|c|}
\hline & \multicolumn{5}{|c|}{ Indices } & \multirow{2}{*}{$\frac{\text { Producto }(\mathrm{H} / \mathrm{s} \text {. }}{(6)}$} \\
\hline & (1) & (2) & (3) & (4) & (5) & \\
\hline $1795 \ldots \ldots \ldots \ldots \ldots$ & 70 & 94 & 107 & 104 & 102 & 29.109 \\
\hline $1796 \ldots \ldots \ldots \ldots$ & 86 & 74 & 78 & 105 & 106 & 29.508 \\
\hline $1797 \ldots \ldots \ldots \ldots \ldots$ & 93 & 103 & 87 & 102 & 103 & 28.700 \\
\hline $1798 \ldots \ldots \ldots \ldots$ & 125 & 104 & 111 & 106 & 108 & 29.801 \\
\hline $1799 \ldots \ldots \ldots \ldots$ & 92 & 72 & 100 & 103 & 103 & 28.888 \\
\hline 1800 & 66 & 52 & 81 & 87 & 82 & 24.330 \\
\hline $1801 \ldots \ldots \ldots \ldots$ & 99 & 72 & 85 & 97 & 101 & 27.314 \\
\hline $1802 \ldots \ldots \ldots \ldots \ldots$ & 105 & 103 & 110 & 101 & 102 & 28.347 \\
\hline $1803 \ldots \ldots \ldots \ldots$ & 81 & 59 & 67 & 79 & 60 & 22.091 \\
\hline $1804 \ldots \ldots \ldots \ldots \ldots$ & 136 & 120 & 113 & 116 & 133 & 32.677 \\
\hline $1805 \ldots \ldots \ldots \ldots \ldots$ & 124 & 114 & 112 & - & - & - \\
\hline $1806 \ldots \ldots \ldots \ldots$ & 113 & 191 & 118 & - & - & - \\
\hline $1807 \ldots \ldots \ldots \ldots \ldots$ & 109 & 142 & 130 & - & - & - \\
\hline
\end{tabular}

(1) Monasterio de Monfero; (2) Priorato de Carballar (Aranga); (3) Priorato de Porto (Pontedeume); (4) 70 parroquias: cereales y habas; (5) 70 parroquias: maiz; (6) 70 parroquias: total cereales y habas. FuENTES: AHRG, Monasterios, Cajas 350 y 450; AHDS, Serie general, leg. 1213.

ma exacta, el diezmo, y otra de forma muy aproximada, el producto agrario bruto. Veamos cómo podemos determinar las restantes.

Sobre la relación simiente-producto disponemos de informaciones parciales para el caso gallego. A partir de las estimaciones realizadas por J. M. Pérez hemos considerado que en el caso de los cereales tradicionales y las habas se obtenian 5 unidades por cada una sembrada, es decir, deduciremos el $20 \%$ del producto bruto en concepto de simiente. Para el maíz hemos elegido un ratio del $5 \%$. En los cálculos sobre las oscilaciones anuales del producto neto hemos considerado que cada cultivador ha empleado la misma cantidad de simiente en cada uno de los años analizados, obtenida de aplicar los ratios citados $(20$ y $5 \%$ ) a la media trienal del producto bruto de cada cereal. A falta de estimaciones precisas sobre los rendimientos por simiente en la Galicia interior hemos escogido unos ratios relativamente «optimistas» porque pensamos que se ajustan mejor a las explotaciones que estamos analizando, las cuales probablemente disponian de una capacidad de abonado y de un porcentaje de tierras de buena calidad superiores a la media.

También reviste especial importancia la determinación de las rentas y exacciones fiscales que pagaba cada explotación, y para ello hemos acudido una vez más al 


\section{CUADRO 9}

Indices de precios de maíz y centeno de diversos prioratos: (1) Almerezo (Ponteceso);

(2) y (5) Callobre (Vilarmaior); (3) Porto (Pontedeume);

(4) y (6) Cinis (Abegondo). Media 1795-1807-100

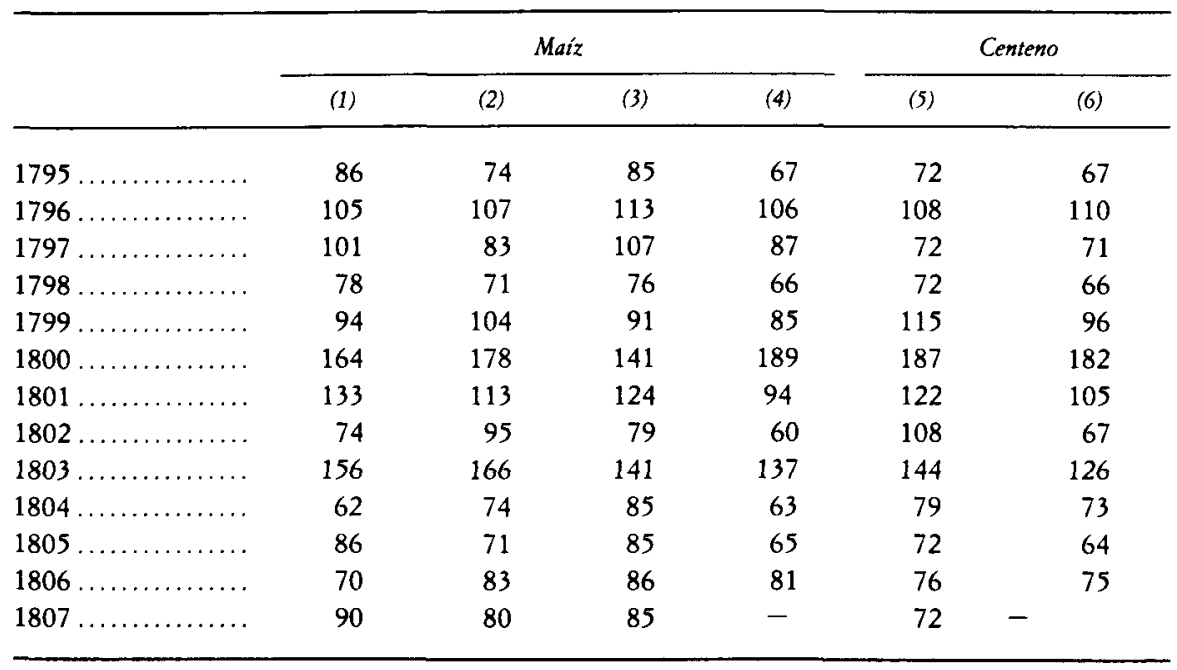

FuENTES: AHRG, Monasterios, Cajas 347-350-449; Archivo del monasterio de San Paio de Antealtares, San Martin, legs. 43 y 46.

Catastro de Ensenada. En la exploración efectuada hemos constatado que los 239 diezmeros de la diócesis de Lugo analizados satisfacian de renta, primicias, oblata, voto, censos, misas, etc., lo siguiente: 9.016 ferrados de centeno ${ }^{35}$ (lo que supuso el $20,75 \%$ de su producción bruta media), 1.108 cántaras de vino (el $8,69 \%$ de su producción total), y 5.658 reales por foros, censos y misas (equivalente al $9 \%$ del valor del resto de las producciones de la explotación sujetas a diezmo). Aunque también se pagaban capones, gallinas o cabritos, el grueso de las rentas era satisfecho en centeno, y suponía por término medio 38 ferrados (algo más de 6 hls.) por explotación, aunque, claro está, encontramos desde campesinos o hidalgos que no declaran pagar ninguna renta, hasta otros que llegan a pagar más de 100 ferrados de centeno, o importantes cantidades en dinero por censos. No obstante, son mayoría los casos en que la renta asciende al $20 \%$ del producto bruto de centeno. En las 64 explotaciones de la muestra que producen vino la renta se reparte entre el centeno

35 Hemos convertido en centeno, a precios corrientes, las rentas estipuladas en otros cereales (trigo, menudo) y en castañas. 
y el vino, con un nivel medio de gravamen respecto al producto bruto total semejante al de las explotaciones exclusivamente cerealeras. Insistamos, por último, en que es posible un cierto margen de variación entre las rentas pagadas en 1752 y las satisfechas con posterioridad a esta fecha, pero dado que estamos ante explotaciones que pagaban rentas forales, cuya cuantía solía mantenerse estable durante periodos relativamente largos, parece plenamente aceptable suponer que siguiesen siendo las mismas.

Para trasladar estos resultados al amplio conjunto de parroquias que incluimos en el análisis hemos tenido que adoptar un sistema mixto para, no sin ciertas arbitrariedades, aplicar los niveles de gravamen más ajustados. Deduciremos siempre una cantidad de cereal y otra de vino (si se produce), y consideraremos que la renta supone el $20 \%$ del producto bruto del centeno siempre que éste sea el cereal mayoritario (cuando su producción supera el $60 \%$ del total de cereales). Para las explotaciones que además de cereales producen vino, a la renta a pagar en cereal le añadiremos la renta a pagar en vino. Esta ascendía, de acuerdo con lo observado en el muestreo, al $10 \%$ de su producto bruto.

Estas son, pues, nuestras hipótesis básicas, salvo en dos situaciones:

1. Cuando el maíz es el cereal más importante, como sucede en la Galicia oc. cidental, trasladamos la carga de la renta al maíz, y seguimos manteniendo el supuesto de que se eleva al $20 \%$ de su producto bruto.

2. Cuando la producción de vino es la más importante (superando el $60 \%$ de la producción total de cereales, castañas, habas y vino), hemos supuesto que la renta principal es la pagada en vino y que equivale al $20 \%$ de su producción, y hemos mantenido la deducción del $20 \%$ del cereal mayoritario en concepto de renta. Con este supuesto pretendemos estimar mejor la carga real que suponía la renta de la tierra en las comarcas orensanas de monocultivo vitícola, donde predominaban las rentas pagadas en vino y a un nivel de gravamen superior al que detectamos en el sur de Lugo ${ }^{36}$.

De la misma forma que en la elección de los coeficientes simiente-producto hemos procurado ser «optimistas», en la estimación de la carga que suponía la renta de la tierra para los mayores productores hemos pretendido no «sobrecargar» de rentas a las explotaciones que seguramente tenian un porcentaje de tierras alodiales o poco gravadas más alto que el resto de las explotaciones.

Para verificar si las hipótesis que hemos escogido eran o no acertadas hemos tomado el conjunto de explotaciones de las que sabemos a ciencia cierta cuánta

36 Sobre las modalidades de pago de la renta de la tierra y su nivel de gravamen en las zonas viticolas, véase Saavedra, (1992a). 
renta pagaban, y hemos comparado las cifras de producto neto y disponibilidades calóricas netas en dos supuestos: deduciendo las rentas que figuran en la documentación, y, por otro lado, aplicando los supuestos de carácter general que acabamos de describir. Las diferencias son minimas: el producto neto de centeno de los 239 vecinos es en el primer caso de $3.433 \mathrm{hls}$., y en el segundo, de 3.576; el de maíz pasa de 1.396 a 1.309; y el de vino, de 1.949 a 1.828. La media de calorias disponibles por explotación apenas varía: de 17.164 a 17.153 .

\section{BIBLIOGRAFIA}

Barreiro Mallón, Baudilio (1990): «El dominio de la familia de los Porras y la evolución de las rentas agrarias en la Tierra de Santiago», Obradoiro de Historia Moderna, 1, pp. 25-45.

Blum, Jerome (1978): The End of the Old Order in Rural Europe, Princeton.

CARMONA BADIA, Joám (1986): «A formaçom do atraso económico. Alguns elementos de historia comparada», en X. Castro, y J. de Juana (eds.) (1986), Segundas Xorradas de Historia de Galicia, Orense, pp. 85-107.

- (1990): El atraso industrial de Galicia, Barcelona.

Clapmam; J. H. (1951): The Economic Development of France and Germany, 1815-1914, Cambridge.

Cordero, Xosé; Fausto Dopico y María Xosé Rodriguez (1983): «A distribución espacial do gando en Galicia segundo o Cadastro de Ensenada», Revista Galega de Estudos Agrarios, 9, pp. 71-83.

DomingueZ MarTiN, Rafael (1990): «Transición del Antiguo Régimen en la sociedad rural del área cantábrica», en Garcia Merino, L. et al (comp.), Los espacios rurales cantábricos y su evolución, Santander.

- LanZA, Ramón (1991): «Propiedad y pequeña explotación en Cantabria a fines del Antiguo Régimen», en P. Saavedra, y R. Villares, Señores y Campesinos en la Peninsula lbérica, siglos XVIII.XX, vol. 2, Barcelona.

Dopico, Fausto y María Xosé Rodriguez (1981): Crisis agrarias ycrecimientoeconómico en Galicia en el siglo XIX, Sada.

- y Robert Rowland (1990): «Demografía del Censo de Floridablanca. Una aproximación", Revista de Historia Económica, VIII, 3, pp. 591-618.

Ellis, Frank (1988): Peasant Economics, Cambridge.

ESSEMYR, Mats (1986): «Food, Fare and Nutrition. Some Reflections on the Historical Development of Food Consumption», The Scandinavian Economic History Review, 2, pp. 76-89.

FERNANDEZJUSTO, Maria (1986): La metrología tradicional gallega. Aportación a los estudios sobre el medio rural, 2 vols., Madrid.

FLoRISTAN ImIzCOz, Alfredo (1982): La Merindad de Estella en la Edad Moderna: los hombres y la tierra, Pamplona.

Lis, C. y H. Soly (1977): «Food Consumption in Antwerp between 1807 and 1859: A Contribution to the Standard of Living Debate», Economic History Review, 3, pp. 460486. 
Livi-BACCI, Mássimo (1988): Ensayo sobre la historia demográfica europea. Población y alimentación en Europa, Barcelona.

Pérez Garcia, José Manuel (1979): Un modelo de sociedad rural de Antiguo Régimen en la Galicia costera: la Peninsula del Salnés, Santiago.

- (1982): «O millo en Galicia: un estado da cuestión», Revista Galega de Estudios Agrarios, $7-8$, pp. $87-104$.

ROSELLO, Jaume (coord.) (1989): El libro de la cocina natural, Barcelona.

SaAvedra Fernández, Pegerto (1988): «Casa y comunidad en la Galicia interior, 1750. 1860 », en Bermejo Barrera, J. C. (coord.), Parentesco, familia y matrimonio en la bistoria de

Galicia, Santiago, pp. 95-143.
(1992a): «La economia viticola en la Galicia del Antiguo Régimen», Agricultura y Sociedad, 62, pp. 111-166. (1992b): A vida cotián en Galicia de 1550-1850, Santiago.

SaAvedra, Pegerto y Ramón Villares (1985): «Galicia en el Antiguo Régimen: la fortaleza de una sociedad tradicional», en R. Fernández (ed.), España en el siglo xVIII. Homenajea Pierre Vilar, Barcelona, pp. 434-504.

Scotr, James C. (1976): The Moral Economy of the Peasant, New Haven.

Shammas, Carole (1984): «The Eighteenth-Century English Diet and Economic Change», Explorations in Economic History, 21, pp. 254-269.

SIMPSON, James (1989): «La producción agraria y el consumo español en el siglo XIX», Revista de Historia Económica, VII, 2, pp. 355-388.

Toutain, Jean-C.: «La consommation alimentaire en France de 1789 à 1964», Cabiers de IT.S.E.A., V, núm. 11, pp. 1909-2049.

VIllares Paz, Ramón (1982): La propiedad de la tierra en Galicia, 1500-1936, Madrid. 